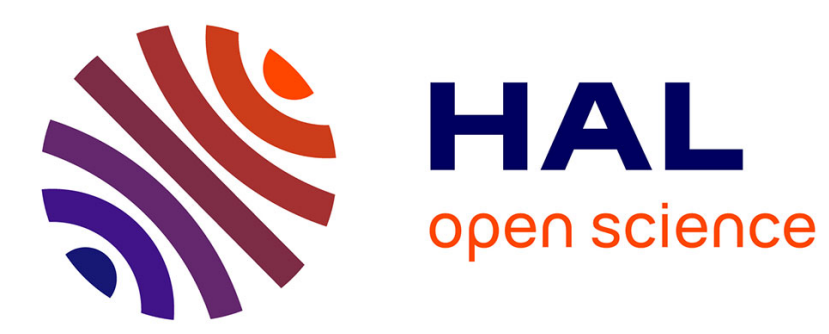

\title{
Experimental investigation of the physical mechanisms governing the spread of wildfires
}

\author{
Frédéric Morandini, Xavier Silvani
}

\section{To cite this version:}

Frédéric Morandini, Xavier Silvani. Experimental investigation of the physical mechanisms governing the spread of wildfires. International Journal of Wildland Fire, 2010, 19, pp.570-582. 10.1071/WF08113 . hal-00591022

\section{HAL Id: hal-00591022 \\ https://hal.science/hal-00591022}

Submitted on 6 May 2011

HAL is a multi-disciplinary open access archive for the deposit and dissemination of scientific research documents, whether they are published or not. The documents may come from teaching and research institutions in France or abroad, or from public or private research centers.
L'archive ouverte pluridisciplinaire HAL, est destinée au dépôt et à la diffusion de documents scientifiques de niveau recherche, publiés ou non, émanant des établissements d'enseignement et de recherche français ou étrangers, des laboratoires publics ou privés. 
1 Experimental investigation of the physical mechanisms governing the spread of wildfires

\author{
Frédéric Morandini* and Xavier Silvani
}

\author{
Laboratoire Sciences Pour l'Environnement, U.M.R. C.N.R.S. 6134, \\ Université de Corse, campus Grimaldi, 20250 Corte, France. \\ * Corresponding author. Telephone: +33 495450 243; fax: +33 495453 326; \\ email: frederic.morandini@univ-corse.fr
}

\title{
Abstract
}

One of the objectives of the present study is to gain a deeper understanding of the heat transfer mechanisms that control the spread of wildfires. Five experimental fires were conducted in the field across on plots of living vegetation. The lengths of the ignition lines were set in the range of $20-30 \mathrm{~m}$ to reproduce wildfire front conditions as closely as possible. The experiments were performed under various vegetation properties, wind conditions and plot topography to highlight different fire spread behaviours. This study focused on characterising heat transfer ahead of the flame front. The temperature and heat flux were measured at the top of the vegetation as the fire spread. The results showed the existence of two different fire spread regimes that were either dominated by radiation or governed by mixed radiant-convective heat transfer. For plume-dominated fires, the flow strongly responds to the great buoyancy forces generated by the fire; this guides the fire plume upward. For wind-driven fires, the flow is governed by inertial forces due to the wind, and the fire plume is greatly tilted towards unburned vegetation. The correlations of the temperature (ahead of the flame front) and wind velocity fluctuations change according to the fire regime. The longitudinal distributions of the radiant heat flux ahead of the fire front are also discussed. The data showed that neither the convective Froude number nor the Nelson convection 
number - used in the literature to predict fire spread regimes - reflect the observed behaviour of wind-driven fires.

Keywords: wildfires; field experiments; temperature; heat transfer; radiation.

\section{Introduction}

Experimental fires have been widely used in fire research to further our understanding of the complex mechanisms governing the behaviour of fires. A large number of experiments have been carried out at the laboratory scale to study fires propagating across fuel beds (Dupuy 1995, Mendes-Lopes et al. 2003, Viegas et al. 2004). These reduced-scale experiments allow the observation of the main features encountered in wildfires and even some specific behaviour such as eruptive fire (Viegas 2006). However, fire is a scale-dependent process (Pitts 1991), and studying a fire as it spreads under full-scale conditions appears more relevant than across small fuel beds. Indeed, flame front properties (height, irradiance, etc.) and the resulting heat transfer mechanisms in the laboratory are not of the same order of magnitude as those in the field. In a previous work (Silvani and Morandini 2009), a comparison of radiation levels impinging ahead of flame fronts, with heights in the range of 0.3-6 m, exhibited significant differences. Therefore, real-scale fire experiments that are representative of most of the physical processes involved in wildfires are needed to gain a deeper understanding of how they spread and to establish useful safety distances for fire managers. To this end, measuring devices dedicated to wildfire applications must be developed, since instrumentation in the field has raised logistical problems that need to be overcome.

Some experimental fires were conducted on a large scale (Cheney et al. 1993, Cheney and Gould 1995, Fernandes 2001, Carrega 2002, Viegas et al. 2002, Bilgili and Saglam 2003, De 
Luis et al. 2004, Vega et al. 2006). However, these studies only provided observations or measurements of the macroscopic characteristics of the flame front (rate of spread, flame length, flame tilt angle, residence time, etc.). Temperature and heat fluxes were measured less frequently (Packam and Pompe 1971, Gould et al. 1997, Butler 2003, Stocks et al. 2004, Butler et al. 2004, Cohen 2004, Silvani et al. 2005, Santoni et al. 2006, Morandini et al. 2006, Silvani and Morandini 2009). The data available in the related literature are summarised in Table 1.

Such measurements, obtained on a large scale, are also needed to improve and validate physical-based modelling of wildfires (Morvan and Dupuy 2004, Linn and Cunningham 2005, Porterie et al. 2005a, Mell et al. 2007). Caution should be exercised when predicting fire spread with models or sub-models developed from and/or validated against laboratory experiments, since these formulations can be misleading when applied to large-scale fire scenarios. For instance, if thermal degradation of the vegetative fuel is modelled by laws established for low heating rates or low masses of the samples, i.e. conditions which are not representative of the mechanisms involved in wildfire spread, extrapolation to a larger scale is prone to errors. Measurements obtained from large-scale experiments are also expected to provide some guidance or validate predictions of fire safety zones (Butler and Cohen 1998, Dupuy and Morvan 2005, Kaiss et al. 2007) and wildland urban interface dimensioning (Cohen 2004, Consalvi et al. 2005, Porterie et al. 2005b). Some of these modelling approaches (Butler and Cohen 1998, Cohen 2004, Kaiss et al. 2007, Zarate et al. 2008) are based on purely radiative models in which the role of convection is neglected - an approach that may not be correct. Indeed, previously proposed physics-based models of fire spread under wind-blown conditions (Pagni and Peterson 1973, Porterie et al. 2000, Morvan and Dupuy 2004, Mell et al. 2007, Morvan et al. 2009) predicted the existence of a significant convective flux on top of the fuel layer in some configurations. 
Fire spread results from the interaction of many processes: heat and mass transfer, thermal degradation of the combustible material and reactions in gaseous and solid phases. Understanding the heat transfer mechanisms governing fire propagation across vegetative fuels is thus of great interest in fire research and forest management. Fire grows and spreads across vegetative fuels by direct burning, which results from impingement of the flame on combustible materials, and from heat transfer towards the unburned fuel by means of radiation and/or convection (combustion products). Environmental factors such as wind, topography and vegetation type can affect the rate and direction of heat transfer and resulting fire spread. These parameters can be controlled in small-scale experiments in the laboratory. However, the slope, fuel and particularly wind are hardly controllable when conducting fire experiments in the field, i.e. under conditions close to those encountered in wildfires. The variability of these conditions in the open explains the drastic changes in fire dynamics which are responsible for many firefighter casualties during interventions. The most significant effects are observed in the flame front properties and dynamics. The volume of reacting gases, amount of heat release and the span of incident radiation can increase by several orders of magnitude during fire spread; even for a given set of ambient conditions, the fire front can propagate within a wide range of spread rates (Viegas 2006). This is the main reason why it is difficult to extrapolate fire spread mechanisms from the laboratory to the field. Data collection in the field is thus the best alternative for understanding the fire spread processes and for validating or improving models. These considerations are the main motivation for developing new measurement devices capable of collecting data in the field during fire spread. 
103 Fire experiments procedure

104 Five experimental fires were conducted in the Mediterranean region (south of France) across

105 plots of shrublands. The fires were lit along the windward edge of the plots using a petrol 106 torch. The lengths of the ignition lines were $20-30 \mathrm{~m}$ to replicate wildfire conditions. The 107 orientation of the plot was chosen according to the main prevailing wind direction to ensure 108 wind-aided fire spread conditions. A detailed description of the plot characteristics and 109 environmental conditions are provided in Table 2. The experiments were conducted under 110 various vegetation properties, wind conditions and plot topography, but the focus of this study 111 was on characterising the heat transfer ahead of the flame front.

\section{Plots and fuel properties}

114 Plots with vegetative fuel as homogeneous as possible and high vegetation cover (coverage > $11595 \%)$ were chosen for the fire experiments. The basic properties of the vegetation were 116 measured and are provided in Table 2. The dominant species were Syrmatium glabrum, 117 Arbutus unedo, Genista lobelia, Erica arborea and Asphodelus albus. Before the fire 118 experiments, the total fuel load (dead and live fuel from litter and canopy) and vegetation 119 height were measured from three sample areas of $1 \mathrm{~m}^{2}$ in size. Samples were taken close to

120 the experimental plots so that the vegetation cover would not be modified. Fuel moisture 121 content was obtained from three samples of the most abundant species. Samples were oven122 dried at $60^{\circ} \mathrm{C}$ for $24 \mathrm{~h}$, and the fuel moisture was expressed as a percentage of the dried 123 weight (Allgöwer et al. 2006). The amount of fuel removed by the fire, i.e. the fuel 124 consumption, was expressed as the ratio of the amount of char remaining after the fire, over 125 the three $1 \mathrm{~m}^{2}$ sample areas, to the fuel load. 
The heat flux and gas temperature during the fire spread experiments were measured by an intrusive sensor system capable of resisting the fire (Silvani and Morandini 2009). The device consists of two heat flux gauges and a thermocouple fixed to a steel support facing the approaching fire front. It is designed to be fast and easy to set up (less than $30 \mathrm{~min}$ ) with the possibility to be deployed in forest fires. The inside of the device was coated with a $4-\mathrm{cm}$ thick layer of insulating material (ceramic felt); the inside temperature never exceeded $70^{\circ} \mathrm{C}$ during the experiments. In every case, the measurements were made close to the top of the vegetation using different supporting rods. A photograph of this device is shown in Fig. 1.

The gas temperature was measured using a K-type thermocouple with a 250 - $\mu$ m-diameter grounded junction. This configuration was chosen to guarantee a good compromise between accuracy and resistance; fine wire thermocouples are less affected by radiation effects and have a faster response (Cox and Chitty 1985), which allows the rapid fluctuations of the gas temperature to be recorded with good accuracy. The response time of the thermocouples used in this study was less than $0.2 \mathrm{~s}$. Each thermocouple was covered with a ceramic insulator and inserted in a 10-cm-long stainless steel tube, leaving the junction to protrude from the device. These devices provided information on the flame residence time and peak temperature.

The total and radiant heat fluxes emitted from the flame front during the fire spread were measured with Medtherm transducers (16H and 64 Series). A sapphire window attachment was added to the radiant heat flux transducer to eliminate the convective heat being transferred to the sensing area. These transducers were calibrated by the manufacturer to 0 $200 \mathrm{~kW} \mathrm{~m}^{-2}$ and had a response time of less than $0.25 \mathrm{~s}$, which provided accurate measurements for an approaching fire front. The transducers were oriented towards the flame front and had a view angle of $150^{\circ}$. A thermocouple recorded the body temperature of the gauge. 
153 buried $0.3 \mathrm{~m}$ under the ground surface to protect it from the fire. Extension cables insulated 154 by a Teflon coating, a layer of ceramic and an outer layer of aluminium connected the sensors to the underground data logger by passing through the steel tube of the support carrying the sensors. This configuration was chosen to allow the use of short extension cables $(1.5 \mathrm{~m})$ to reduce the measurement errors. The transducers signals were recorded at a sampling rate of 1 Hz. This sampling frequency matched the response time of the sensors used. influencing fire spread (Cheney et al. 1993). The wind velocity and direction were recorded

161 using a two-dimensional ultrasonic anemometer $2.5 \mathrm{~m}$ above the ground surface to reflect the

162 average wind acting on the fire front. The anemometer was located on the downwind edge of 163 the vegetation plot to minimise the influence of the fire on the wind measurements. 164 Furthermore, such a location protected the ultrasonic transducers from smoke and large165 diameter firebrands generated by the fire which can affect sonic measurements. The wind data 166 were recorded using another (synchronised) data logger at a sampling rate of $1 \mathrm{~Hz}$.

167 Finally, to obtain accurate observations of the fire spread, three digital video cameras were 168 used to record the rear, front and side views of the fire. The video recordings (25 images per 169 second) provided information on the rate of fire spread and the geometric properties of the 170 flame, i.e. the flame height and tilt angle. A virtual grid was drawn on the video images by 171 means of reference marks placed regularly every $5 \mathrm{~m}$. The known positions of these marks 172 helped to relate the position and dimensions of the flame on the virtual grid to its real position 173 and dimensions on the field. The rate of spread was obtained from the slope of the curve 174 representing the fire front position versus time. About eight data points were obtained for 175 each curve by timing the arrival of the fire front head to the reference marks. A least squares 176 regression was used to fit a straight line to these points. The flame front depth was computed 
177 from the product of the residence time and the rate of spread. The flame length and height

178 were defined along the mean flame axis and the vertical, respectively. The flame tilt angle

179 was defined as the angle between the terrain and the leading surface of the flame.

182 Results and discussion

183 Fire front properties and behaviour

184 Every experimental plot was ignited as a line fire along the windward plot edge; the fire fronts developed a curvilinear shape during their spread. Details of the environmental conditions and related fire properties are reported in Table 2. The average wind properties remained nearly constant during the experiments, and the fires reached a quasi-steady state. The steady correlation factors $\left(R^{2}\right)$ for the least squares regression, which was computed to obtain the rate of spread, were in the range of $0.86-0.96$. These high $R^{2}$ values are a good indicator of fire steadiness. The vegetative fuels were mostly composed of fine materials (needles, leaves and twigs) with diameters that were lower than $2 \mathrm{~cm}$; consequently, the fuel consumption was

192 very high for the set of experiments. The fireline intensity, which represents the heat released

193 per unit time per unit length of the fire front, is defined as the product of the weight of fuel consumed $\left(\mathrm{kg} \mathrm{m}^{-2}\right)$, the heat yield of the fuel (assumed to be $18000 \mathrm{~kJ} \mathrm{~kg}^{-1}$ for most

195 vegetative fuel) and the rate of spread $\left(\mathrm{m} \mathrm{s}^{-1}\right)$. The measured fire intensities were in the range 196 of $8300-31000 \mathrm{~kW} \mathrm{~m}^{-1}$. These values are consistent with the intensities measured during the 197 experiments across similar fuel loads (Table 1). The high intensities measured during 198 experiments $1-3\left(16000-31000 \mathrm{~kW} \mathrm{~m}^{-1}\right)$ can be attributed to the significant fuel load (4.1$1997.4 \mathrm{~kg} \mathrm{~m}^{-2}$ ) of particular vegetal species (Syrmatium glabrum and Genista lobelia). Fire tests conducted across these broom species, which are very inflammable, generate high intensities

201 with fire fronts travelling very fast even under low-risk conditions (wind velocity $<5 \mathrm{~m} \mathrm{~s}^{-1}$, 
high fuel moisture content). It should be noted that post-fire measurements were performed at 203 least $1 \mathrm{~h}$ after the passage of the fire front, when the temperature had decreased to a sufficient extent to allow the safe sampling of the remaining char. During this time period, mass loss continued due to char oxidation from large-diameter materials $(>2 \mathrm{~cm})$ which did not participate in the spreading of the pyrolysis front; thus, the amount of fuel actually consumed within the flaming front was overestimated. Furthermore, the rate of spread was determined at the fire head or at the most advanced point of the fire front; this was because the initial straight line of ignition was observed to change to a parabolic shape when quasi-steady propagation was achieved. Both sources of errors contributed to overestimation of the fireline 211 intensity.

Qualitative observations of the fire spread from video recordings revealed the 213 existence of two types of fires according to the flame front properties and behaviour. 214 Photographs of the fire spread in experiments 2 and 4 are shown in Fig. 2. In the first type of 215 fire (experiments 1, 2 and 3), the flames stood up (flame heights were about $5 \mathrm{~m}$ ) and the 216 smoke plume was guided upwards to produce a nearly vertical convection column. The flow 217 strongly responded to the heating and buoyancy forces generated by the fire (Fig. 2a), and no 218 smoke was observed to flow ahead of the fire front. In the second type (experiments 4 and 5), 219 the inertial forces exceeded the buoyancy forces, and the flow did not respond to heating 220 generated by the fire. In this case, the buoyancy forces generated by the fire were weaker 221 because of the lower fuel load. The flame front was greatly tilted forward (Fig. 2b), and the 222 flame height was about $1.5 \mathrm{~m}$. The top of the unburned vegetation layer was subjected to 223 intermittent lapping by the flames, and the fire travelled quickly across the vegetation. The smoke flowed close to the top of the vegetation, embedding the unburned vegetation within a layer of hot gases released by combustion. In the following sections, the effects of the fire 226 behaviour on the temperature and heat flux measurements are examined. 
229 Thermocouples are commonly used in fire research to measure gas temperatures, but they 230 often fail to measure the true gas temperature (Cox and Chitty 1985, Luo 1997, Dupuy et al. 231 2003, Silvani and Morandini 2009). Radiation effects that depend on the measurement 232 conditions are the most significant sources of errors. Discrepancies between the true and measured gas temperatures are considered acceptable since the error range of the probes used in this study is less than $10 \%$ (Silvani and Morandini 2009). The corrected temperature curves are not provided here, but the effects of radiation on the thermocouple measurements must be kept in mind.

The flame residence time for each experiment is listed in Table 2 and is defined as the time during which the temperature is greater than $500^{\circ} \mathrm{C}$, which corresponds to the visible flame temperature (Drysdale 1985). The flame residence times did not show significant differences and thus could not account for the two fire spread behaviours identified previously.

The temperature-time curves for the five experiments are shown in Fig. 3. The air 242 temperature measured during the fire spread showed the presence of three regions: preheating, 243 flaming and charring. These regions are delineated by two vertical dashed lines in Fig. 3, using the previously defined flame temperature criteria. The measured temperatures began at the ambient temperature and increased to a maximum of about $800-900^{\circ} \mathrm{C}$, which is the usual temperature range for burning vegetal fuels. The temperature curves show a slow trend 247 modulated by fast fluctuations. The slow trend, or the low-frequency part of the signal, is 248 related to the fire spreading, while the fluctuations are due to flame pulsations and wind gusts 249 (Morandini et al. 2006).

250 In the first group of experiments, the air temperature remained close to the ambient value 251 before the arrival of the fire front. The rate of the rise in air temperature from ambient to 
252 ignition was computed from low-pass filtered signals (Silvani et al. 2005) and is provided in 253 Table 2. The corresponding flame fronts (Fig. 2a) were close to the vertical, and the smoke 254 plume was guided upward. Some peculiarities in the temperature behaviour were observed in experiment 2 . The temperature suddenly dropped to $200^{\circ} \mathrm{C}$ for about $20 \mathrm{~s}$ due to the presence of discontinuities in the fuel; these resulted from animal paths that passed through the 257 experimental plot. These discontinuities induced local extinction of the fire. The measurements made in the preheating region, which are of greater interest, were not influenced by this vegetation discontinuity. The rising temperature rate during preheating in the second group of experiments was about one-fifth lower than that in the first group. 261 Furthermore, the increase in air temperature occurred over a longer period before flame 262 contact (more than $100 \mathrm{~s}$ prior to the ignition of vegetation), and the temperature measurements showed high fluctuations. These fluctuations were higher in the second group than in the first because of the presence of the smoke plume as well as the intermittent lapping at the top of the vegetation by the flame (Fig. 2b).

Computing the correlation coefficient and related confidence intervals helps to determine if a statistical relation exists between temperature and wind velocity fluctuations. The 268 correlation coefficient between temperature and velocity is given by:

$$
r=\frac{\operatorname{cov}(T, u)}{\sigma_{T} \sigma_{u}}
$$

270 where $\operatorname{cov}$ is the covariance of temperature $T$ and longitudinal wind velocity $u$, and $\sigma$ is the 271 standard deviation. The square of $r$, namely, the coefficient of determination $r^{2}$, is used to 272 measure the association between both variables. The coefficient of determination is the 273 fraction of the variance in $u$ that is accounted for by changes in $T$ and the linear relationship 274 between $u$ and T. A confidence level of $95 \%$ and sample size of $100 \mathrm{~s}$ were chosen. As expected, the correlation between temperature and wind velocity was better in the second 
group of experiments $\left(r^{2}=0.2\right)$ than in the first group $\left(r^{2}=0.015\right)$. In addition, a confidence 277 level of $80 \%$ and sample size of $200 \mathrm{~s}$ were also tested. In the first group of experiments, the confidence interval width remained at around 0.01 . In contrast, the confidence interval width increased to around 0.2 when either the confidence level increased or the sample size decreased. The $r^{2}$ statistical convergence can thus be enhanced by increasing the sampling rate. The $r^{2}$ value showed a considerable decrease when $r$ decreased by one-tenths of its original value. Indeed, the $r^{2}$ values in the range of $0.2-0.3$ coincided with $r$ values in the range of $0.5-0.6$. In contrast, $r$ was about 0.1 when $r^{2}$ was lower than 0.05 . Although the correlation between $T$ and $u$ is not linear, a statistical relation cannot be ignored in the second group of experiments, while it can be neglected for the first group. In other words, wind did not significantly influence heat transfer ahead of the flame front in the first group of experiments. Conversely, in the second group of experiments, coupling between wind and temperature was observed in the preheating region. Indeed, the correlation coefficient between temperature and velocity as well as the fluctuating nature of the temperature signal suggest the presence of convective heat transfer in the preheating region. In this case, the unburned vegetation was embedded into a wind-driven smoke layer (Fig. 2). However, to 292 obtain a correct representation of the heat transfer processes governing fire spread, it was necessary to simultaneously use several sensors scattered through the vegetation plot during the experiments. The mechanisms governing heat transfer towards unburned vegetation may be different at the fire head or flanks. Numerical simulations in the presence of an ambient wind (Mell et al. 2007) showed that the flanks of the fire perimeter spread under conditions alternating between heading and baking fires, which influences the heat transfer processes. In general, because the information collected by a thermocouple is local in nature, it is not adequate to investigate the heat transport phenomena using single-point measurements, and 
measurements of temperature distributions or integral quantities such as heat fluxes should be

301 preferred.

\section{Heat fluxes}

304 The time evolution of the total and radiant heat fluxes measured during the fire spread

305 experiments are shown in Fig. 4. The preheating, flaming and charring regions can also be 306 observed in these curves. The heat fluxes progressively increased up to maximum values exceeding $100 \mathrm{~kW} \mathrm{~m} \mathrm{~m}^{-2}$ when the flame was in contact with the measurement device. However, caution should be exercised in interpreting the heat flux measurements in a mixed radiant-convective environment, especially those obtained from total heat flux gauges. The calibration process consists of determining the sensitivity $\left(\mathrm{kW} \mathrm{m}^{-2} \mathrm{mV}^{-1}\right)$ of the transducers in comparison to the output voltage of a known calibration source. The calibration should ideally be performed in a thermal environment similar to the one in which the gauges will be used; however, gauge calibration is usually performed using radiant sources such as a black body,

314 furnace or radiant panel. It may not be entirely appropriate to measure the total heat flux using 315 a Gardon gauge through radiation-based calibration in a mixed radiative-convective 316 environment such as a fire (Bryant et al. 2003). The gauge sensitivity differs for radiative and convective contributions; a method to estimate measurement uncertainties from total gauges

318 in a mixed radiative-convective environment has been proposed (Kuo and Kulkarni 1991).

319 This method allows the total incident flux to be calculated when calibration is based only on 320 radiative flux. Bryant et al. (2003) highlighted the uncertainties caused by convection when 321 radiation is the quantity under consideration and proposed a method to calculate the incident 322 radiant heat flux from total gauges. In both cases, the applied corrections are obtained from 323 the thermal diffusion equation for a foil and are expressed according to the convective heat 324 transfer coefficient or the Nusselt number, which depends on the thermophysical properties of 
the fluid (density, specific heat at constant pressure, viscosity and thermal conductivity) in contact with the gauge, the velocity of the fluid, the flow regime (turbulent or laminar), the nature of convection (natural or forced convection) and the geometry of the surface of the heated gauge. The uncertainties in determining the parameters of the correction method, i.e. the convective heat transfer coefficient or the Nusselt number, make these corrections difficult to apply. A previous work (Silvani and Morandini 2009), quantified the error when following

331 the method proposed by Kuo and Kulkarni (1991); it was determined that the total heat flux is underestimated in the flaming region.

The radiation heat flux transducers are not subject to such uncertainties since the window attachment eliminates convection. Nevertheless, these gauges may suffer from deposition of soot on the sapphire window attachment. The use of gas purging eliminates soot deposition, 336 but this is not easy to implement in the field. To clarify the deposition of soot on the radiometer window, a preliminary study was conducted in the laboratory using fires from a 338 forest fuel burner (Appendix 1). The results showed that the deposition of soot on the gauge 339 window can be considered negligible when the radiometer is only exposed to smoke, but 340 flame contact with the gauge leads to the deposition of a significant quantity of soot on the 341 window. For this reason, the radiation heat flux gauges underestimate radiation inside sooty 342 flames; thus, only the measurements ahead of the fire front are considered in the following 343 sections.

344 Using two different gauge types allows the qualitative partitioning of the convective and 345 radiative processes in the preheating region. When the total and radiation heat fluxes coincide, 346 heat transfer ahead of the fire front is dominated by radiation, and gauges provide accurate 347 quantitative measurements. Conversely, greater discrepancies between the two signals 348 indicate preheating due to mixed radiant-convective heat transfer. By integrating the heat flux 349 curves ahead of the flame front, the differences between radiation and total heat fluxes can be 
evaluated in the preheating region. In the first group of experiments, these differences were

351 lower than $10 \%$, so radiation could be considered as the dominant heat transfer process ahead

352 of the fire front. In the second group of experiments, the measurements revealed the nonnegligible contribution of convective preheating for the unburned fuel, but the heat flux levels were lower. The difference between the radiation and total heat fluxes was as great as $50 \%$ (experiment 4). These results confirm the existence of a convective component ahead of the

356 flame front. The significant role of convective heat transport in the overall thermal balance ahead of the flame front is related to the stronger correlation between fluctuating temperature and wind velocity fields. This study did not focus on the quantitative measurement of the convective exchange between the hot gas stream and vegetation. Aside from the previously 360 mentioned problems of radiation-based calibration for total heat flux gauges in a mixed environment, the convective heat transfer coefficient of the transducer was different from that of the fuel particles. The geometric properties (shape and orientation) and thermal conductivity of the fuel particles should be taken into account to estimate convective heating

364 from the viewpoint of the vegetation. Furthermore, the vertical velocity profile within the vegetation has significant effects on advection, and convective heating varies within the fuel layer. For instance, quantitative measurements of the convection above the vegetation can be performed by determining the temperature and velocity fields using thermocouples and particle image velocimetry, respectively.

Heat transfer mechanisms governing fire spread

371 The different heat transfer processes ahead of the fire front that are observed between the two groups of experiments are influenced by changes in the fire plume properties and affect the

373 time needed for the unburned vegetation to ignite. The time during which the unburned 374 vegetation is exposed to a radiation heat flux greater than $13 \mathrm{~kW} \mathrm{~m}^{-2}$ is provided in Table 2 
375 for the set of experiments. This threshold value corresponds to the minimum radiation heat

376 flux needed to ignite volatile matter from the vegetative fuels by a pilot flame (Drysdale,

377 1985). The exposure time to radiation was significantly longer in the first group of experiments than in the second group. These results show that in the first group of experiments, the preheating mechanisms ahead of the fire front were governed by radiation.

The longitudinal variation in the radiation heat flux impinging upon the unburned vegetation is shown in Fig. 5. The data were deduced from flux-time measurements considering a steady rate of fire spread. The flux-time signals were first filtered before timeto-space transformation with a Butterworth filter to eliminate high signal frequencies (Silvani et al. 2005). This process allowed a better representation of the mean spatial distribution for radiation impinging ahead of the fire front. The distance to the fire front was estimated by multiplying the time to ignition by the rate of spread for each experiment. The spatial distribution of the heat fluxes ahead of the flame front confirmed the existence of two fire spread processes. In the first group of experiments, radiation ahead of the flame front presented some characteristic length scales or impact distances (lengths across which radiation level was greater than the threshold of $13 \mathrm{~kW} \mathrm{~m}^{-2}$ ) of about three times the flame

391 height. Thermal radiation is a long-range process and is usually considered as the dominant mode of heat transfer, which determines the growth and spread of large-scale fires (Sacadura 2005). Incident radiation plays a significant role in the thermal degradation of the fuel through 394 processes such as water evaporation and fuel pyrolysis. Heat flux measurements were 395 performed above the vegetation; therefore, they are related to the energy impinging on the top 396 of the fuel layer, i.e. the incident radiation. The typical absorptivity of vegetation in the 397 Mediterranean region, which depends on fuel properties (spectral, shape, orientation and 398 moisture content), is around 0.9 with reference to the radiation emitted by a black body at $1000^{\circ} \mathrm{C}$ (Monod et al. 2009). The top of the vegetation absorbed most of the thermal radiation 
measured by the transducers. The radiation mean path length within the vegetation was

401 smaller, as was the radiation penetrating inside the fuel layer.

For experiments $1-3$, the measurements showed significant radiation levels up to $10 \mathrm{~m}$

404 heating began several meters ahead of the flame front. It is argued that the fire spreading

405 scenario, which involves ignition of the mixture formed by these combustible gases and by 406 the oxidiser located ahead of the flame front, is most commonly observed in wildland fires.

407 Most safety criteria (fuel breaks or wildland-urban interfaces) are based on a radiation408 dominated fire spread (Butler and Cohen 1998, Cohen 2004, Zarate et al. 2008). However, the 409 present heat flux measurements indicate the existence of a different scenario. In the second 410 group of experiments, the radiation level ahead of the flame front was lower than $13 \mathrm{~kW} \mathrm{~m}^{-2}$ 411 (Fig. 5); this value is too low for sustained pyrolysis of the vegetative fuel to occur. In this case, the fire spread by convection heating, which is related to the intermittent licking of the 413 top of the unburned vegetation by the flame. Physics-based models developed in previous 414 studies (Morvan and Dupuy 2004, Linn and Cunningham 2005, Morvan et al. 2009) predicted 415 a change in the fire spread regime dominated by either radiation or convection under low or 416 high wind conditions, respectively. This change in the fire spread regime is usually predicted 417 using the convective Froude number $F_{c}$ (Clark et al. 1996) or the convection number $N_{c}$ 418 (Nelson 1993). These dimensionless numbers represent the ratio of the inertial forces induced 419 by wind flow and the buoyancy forces generated by combustion. The convective Froude 420 number and convection number are given by:

$$
F_{c}=\sqrt{\frac{(u-r)^{2}}{g \frac{\Delta \theta}{\theta_{a}} \ell}}
$$

$$
N_{c}=\frac{2 g I}{\rho C_{p} \theta_{a}(u-r)^{3}}
$$


where $u$ stands for the average wind velocity $\left(\mathrm{m} \mathrm{s}^{-1}\right), r$ is the rate of fire spread $\left(\mathrm{m} \mathrm{s}^{-1}\right), g$ is the acceleration due to gravity $\left(\mathrm{m} \mathrm{s}^{-2}\right), \Delta \theta$ is the difference between the temperatures of the hot gases and the surroundings, $\theta_{a}$ is the temperature of the surroundings $(\mathrm{K}), I$ is the fireline intensity $\left(\mathrm{kW} \mathrm{m}^{-1}\right), \rho$ is the air density $\left(1.2 \mathrm{~kg} \mathrm{~m}^{-3}\right)$ and $C_{p}$ is the specific heat of dry air at constant pressure $\left(1.005 \mathrm{~kJ} \mathrm{~kg}^{-1} \mathrm{~K}^{-1}\right)$. The variable $\ell(m)$ is a characteristic length scale of the flame front which is representative of buoyancy forces generated by the fire, i.e. the flame's length, $L$, depth, $D$ or height, $H$. In numerical simulations (Pagni and Peterson 1973, Clark et al. 1996, Morvan and Dupuy 2004, Morvan 2006), researchers suggested that $F_{c}{ }^{2}<1$ (resp. $N_{c}>1$ ) indicates a plume-dominated fire, while $F_{c}^{2}>1\left(\right.$ resp. $\left.N_{c}<1\right)$ indicates a wind-driven fire. In this study, the convective Froude and convection numbers (Table 2) were lower than 0.4 and greater than 14, respectively. These results therefore confirm the conclusions of Sullivan's analysis of grassland fires (Sullivan 2007). Neither dimensionless number reflects the observed behaviour of wind-driven fires at the field scale and both numbers seem more appropriate for quantifying academic fire spread scenarios such as laboratory-scale experiments or numerical simulations. The wind-driven fire spread regime, in which the contribution of convection 439 becomes significant due to contact of the fire plume with unburned vegetation, should be 440 taken into account when managing safety zones. Simulation results (Porterie et al. 2005b, 441 Morvan 2006) also pointed out that convection cannot be neglected in predicting fire safety 442 zones when plume impingement occurs. Morvan and Dupuy (2004) clarified that for wind443 driven fires, radiation and convective heat transfer initially have the same order of magnitude; 444 however, fire propagation is subsequently controlled by convective heat transfer, which can represent up to $70 \%$ of the energy received by the solid fuel. The existence of such a regime,

446 which is favoured by a low fuel load (generating less buoyancy forces) on steep slopes and 447 under wind-aided conditions, suggests that the dimensioning of fuel breaks in vegetal cover 
may not be appropriate if it is based only on a purely radiative evaluation of the impact

449 distance.

\section{Conclusion}

453 The heat transfer mechanisms ahead of a flame front were investigated in the field to further 454 our understanding of how wildfires spread. Within the range of experimental configurations 455 considered (wind velocities $<5 \mathrm{~m} \mathrm{~s}^{-1}$ ), the collected data indicated the existence of two fire 456 spread regimes. The first regime, which occurs for higher fuel loads, is plume-dominated. In 457 this case, the flow strongly responds to the great buoyancy forces generated by the fire: 458 flames and smoke plume are guided upward. Radiation is the dominant heat transfer 459 mechanism ahead of the fire front. The second regime, which occurs for lower fuel loads, is 460 wind-driven. In this case, the flow is governed by inertial forces due to wind: flames and 461 smokes travel close to the top of the vegetation. Preheating of the unburned fuel occurs due to 462 mixed radiant-convective heat transfer. The flame front spreads quickly by direct contact with 463 unburned fuel. Within the range of experimental conditions considered in this study, it was 464 found that the Clark's convective Froude number and Nelson's convection number, which are used in numerical studies to predict the fire spread regime, did not reflect the observed

466 behaviour of the wind-driven fires in the field. The complexity of the turbulent wind flow 467 modified by the fire needs further investigation to assess the role of convective heat transfer 468 in greater detail. Convection can endanger fuel break efficiency or firefighter safety if these 469 distances are determined according to radiation only. 
472 This work was financially supported by the Corsica region. Experiments $2-5$ would not have

473 been possible without the assistance of the French forestry, agriculture and firefighting 474 services (Forestiers Sapeurs, Office National des Forêts, Direction Départementale de

475 l'Agriculture et de la Forêt, Service Départemental d'Incendie et de Secours). We also thank 476 our colleagues from CEREN (Centre d'Etude et de Recherche de l'Entente) for having invited us 477 to their experimental campaign (experiment 1 ).

References

Allgöwer B, Calogine D, Camia A, Cuiñas P, Fernandes P, Francesetti A, Hernando C, Koetz B, Koutsias N, Lindberg N, Marzano R, Molina D, Morsdorf F, Ribeiro Lm, Rigolot E, Séro-Guillaume O (2006) Methods for Wildland Fuel Description and Modelling: A State of the Art. Deliverable D-02-06 EUFIRELAB. http://eufirelab.org.

Bilgili E, Saglam B (2003) Fire behavior in maquis fuels in Turkey. Forest Ecology and Management 184, 201-207.

Bryant RA, Womeldorf CA, Johnsson EL, Ohlemiller T (2003) Radiative Heat Flux Measurement Uncertainty. Fire and Materials 27, 209-222.

Butler BW (2003) Field measurements of radiant energy transfer in fuel scale wind driven crown fires. $6^{\text {th }}$ ASME-JSME Thermal Engineering Joint Conference, 16-20.

490 Butler BW, Cohen J, Latham DJ, Schuette RD, Sopko P, Shannon KS, Jiminez D, Bradshaw LS (2004) Measurement of radiant emissive power and temperatures in crown fires. Canadian Journal of Forest Research 34, 1577-1587.

Butler BW, Cohen JD (1998) Firefighter Safety Zones: A Theoretical Model Based on 494 Radiative Heating. International Journal of Wildland Fire 8, 73-77. fire spread. Canadian Journal of Forest Research 34, 1588-1599. 
Carrega P (2002) Relationships between wind speed and the R.O.S. of a fire front in field conditions: an experimental example from the Landes forest, France. In Proceedings of the $4^{\text {th }}$ International Conference on Forest Fire Research, 2002.

Cheney NP, Gould JS (1995) Fire Growth in Grassland Fuels. International Journal of Wildland Fire 5, 237-247.

Cheney NP, Gould JS, Catchpole WR (1993) The influence of fuel, weather and fire shape variables on fire-spread in grasslands. International Journal of Wildland Fire 3, 31-44.

Clark TL, Jenkins MA, Coen JL, Packham DR (1996) A Coupled Atmosphere-Fire Model: Role of the Convective Froude Number and Dynamic Fingering at the Fireline. International Journal of Wildland Fire 6, 177-190.

Cohen JD (2004) Relating flame radiation to home ignition using modeling and experimental crown fires. Canadian Journal of Forest Research 34, 1616-1626.

Consalvi JL, Porterie B, Nicolas S, Loraud JC, Kaiss A (2005) Modeling Thermal Impact of Wildland Fires on Structures. Part II: Radiative Impact of a Fire Front. Numerical Heat Transfer Part A: Applications 47, 491-503.

Cox G, Chitty R (1985) Some source-dependent effects of unbounded fires. Combustion and Flame 60, 219-232.

Cox G, Chitty R (1985) Some source-dependent effects of unbounded fires. Combustion and Flame 60, 219-232.

De Luis M, Baeza M, Raventos J, Gonzalez-Hidalgo J (2004) Fuel characteristics and fire behaviour in mature Mediterranean gorse shrublands. International Journal of Wildland Fire 13, 79-87.

Drysdale D (1985). An introduction to fire dynamics, Wiley-Interscience, New York.

Dupuy JL (1995) Slope and fuel load effects on fire behavior: laboratory experiments in pine needles fuel beds. International Journal of Wildland Fire 5, 153-164. 
Dupuy JL, Maréchal J, Morvan D (2003) Fires from a cylindrical forest fuel burner: combustion dynamics and flame properties. Combustion and Flame 135, 65-76.

Dupuy JL, Morvan D. (2005). Numerical study of a crown fire spreading toward a fuel break using a multiphase physical model. International Journal of Wildland fire, 14,141-151.

Fernandes PM (2001) Fire spread prediction in shrub fuels in Portugal. Forest Ecology and Management 144, 67-74.

Gould JS, Knight I, Sullivan AL (1997) Physical modelling of leaf scorch height from prescribed fires in young Eucalyptus sieberi regrowth forests in Southeastern Australia. International Journal of Wildland Fire 7, 7-20.

Kaiss A, Zekri L, Zekri N, Porterie B, Clerc JP, Picard C (2007) Fuelbreak efficiency for wildland fire prevention. C. R. Physique 8, 462-468.

Kuo CH, Kulkarni AK (1991) Analysis of heat flux measurement by circular foil gages in a mixed convection/radiation environment. Journal of Heat Transfer 113, 1037-1040.

Linn R, Cunningham P (2005) Numerical simulations of grass fires using a coupled atmosphere-fire model: Basic fire behavior and dependence on wind speed. Journal of Geophysical Research 110, 1-19.

Luo M (1997) Effects of Radiation on Temperature Measurement in a Fire Environment. Journal of Fire Sciences 15, 443-461

Mell W, Jenkins MA, Gould J, Cheney P (2007) A Physics Based Approach to Modeling Grassland Fires. International Journal of Wildland Fire 16, 1-22.

Mendes-Lopes J, Ventura J, Amaral J (2003) Flame characteristics, temperature-time curves, and rate of spread in fires propagating in a bed of Pinus pinaster needles. International Journal of Wildland Fire 12, 67-84.

Monod B, Collin A, Parent G, Boulet P (2009) Infrared radiative properties of vegetation involved in forest fires. Fire Safety Journal 44, 88-95. 
547 Morandini F, Silvani X, Rossi L, Santoni PA, Simeoni A, Balbi JH, Rossi JL, Marcelli T 548 (2006) Fire spread experiment across Mediterranean shrub: Influence of wind on flame 549 front properties. Fire Safety Journal 4, 229-235.

550 Morandini F, Silvani X, Rossi L, Santoni PA, Simeoni A, Balbi JH, Rossi JL and Marcelli T 551 (2006) Fire spread experiment across Mediterranean shrub: Influence of wind on flame 552 front properties. Fire Safety Journal 41, 229-235.

553 Morvan D (2006) A numerical study of flame geometry and potential for crown fire initiation 554 for a wildfire propagating through shrub fuel. International Journal of Wildland Fire 16, $555 \quad 511-518$

556 Morvan D, Dupuy JL (2004) Modelling the propagation of a wildfire through a Mediterranean 557 shrub using a multiphase formulation. Combustion and Flame 138, 199-200.

558 Morvan D, Meradji S, Accary G (2009) Physical modelling of fire spread in grasslands. Fire 559 Safety Journal 44, 50-61.

560 Nelson R. (1993) Power of a Fire - a Thermodynamic Analysis. International Journal of $561 \quad$ Wildland Fire 3, 131-138.

562 Packam DR, Pompe A (1971) Radiation temperatures of forest fires. Australian Forest $563 \quad$ Research 5,1-8.

564 Pagni PJ and Peterson TG (1973) Flame spread through porous fuels. In Proceedings of the $14^{\text {th }}$ Symposium (Int) on Combustion pp. 1099-1107. The Combustion Institute. Pittsburgh. Pitts WM (1991) Wind effects on fire, Progress in Energy and Combustion Sciences 17, 83567 134.

568 Porterie B, Consalvi JL, Kaiss A, Loraud JC (2005a) Predicting wildland fire behavior and 569 emissions using a fine-scale physical model. Numerical Heat Transfer Part A: Applications 47, 571-591. 
571 Porterie B, Morvan D, Loraud JC, Larini M (2000) Firespread through fuel beds : Modelling 572 of wind-aided fires and induced hydrodynamics. Physics of Fluids 12, 1762-1782.

573 Porterie B, Nicolas N, Consalvi JL, Loraud JC, Giroud F, Picard C (2005b) Modeling

574 Thermal Impact of Wildland Fires on Structures. Part I: Radiative and Convective 575 Components of Flames Representative of Vegetation Fires. Numerical Heat Transfer Part $576 \quad$ A: Applications 47, 471-489.

577 Sacadura JF (2005) Radiative transfer in fire safety science. Journal of Quantitative $578 \quad$ Spectroscopy and Radiative Transfer 93, 5-24.

579 Santoni PA, Simeoni A, Rossi JL, Bosseur F, Morandini F, Silvani X, Balbi JH, Cancellieri 580 D, Rossi L (2006) Instrumentation of wildland fire: Characterisation of a fire spreading $581 \quad$ through a Mediterranean shrub. Fire Safety Journal 41, 171-184.

582 Silvani X, Morandini F (2009) Fire spread experiments in the field: temperature and heat flux measurements. Fire Safety Journal, 44, 279-285.

584 Silvani X, Rossi L, Morandini F (2005) The measurements of integral scales in free wildland fires. Proc $4^{\text {th }}$ Mediterranean Combustion Symposium, Lisbon.

586 Stocks BJ, Alexander ME, Lanoville RA (2004) Overview of the International Crown Fire 587 Modelling Experiment. Canadian Journal of Forest Research 34, 1543-1547.

588 Sullivan AL (2007) Convective Froude number and Byram's energy criterion of Australian 589 experimental grassland fires. Proceedings of the Combustion Institute, 2557-2564.

590 Vega JA, Fernandes P, Cuiñas P, Fontúrbel MT, Pérez JR and Loureiro C (2006) Fire spread 591 analysis of early summer field experiments in shrubland fuel types of northwestern Iberia. 592 In Proceeding of the $5^{\text {th }}$ International Conference on Forest Fire Research.

593 Viegas DX (2004) Slope and wind effects on fire propagation. International Journal of $594 \quad$ Wildland Fire 13, 143-156. 
Viegas DX (2006) Parametric study of an eruptive fire behaviour model International Journal of Wildland Fire 15, 169-177

Viegas DX, Cruz MG, Ribeiro LM, Silva AJ, Ollero A, Arrue B, Dios R, Gómez-Rodríguez F, Merino L, Miranda AI, Santos P (2002) Gestosa Fire Spread Experiments. In Proceedings of the $4^{\text {th }}$ International Conference on Forest Fire Research.

Viegas DX, Palheiro PM, Pita LP, Ribeiro LM, Cruz MG, Ollero A, Arrue B, Dios R (2006) Analysis of fire behaviour in Mediterranean shrubs: Gestosa Fire Spread Experiments. In Proceeding of the $5^{\text {th }}$ International Conference on Forest Fire Research.

604

Zarate L, Arnaldos J, Casal J (2008) Establishing safety distances for wildland fires. Fire

605

606

607

\section{Appendix 1}

608

A preliminary study of the deposition of soot on the radiometer window was conducted in the laboratory using two radiation heat flux transducers with sapphire windows and fires from a

610 forest fuel burner. The burner was made from a 50-cm-diameter basket filled with $500 \mathrm{~g}$ of 611 forest fuel (Pinus pinaster needles) and ignited using alcohol. Prior to each fire test, both 612 radiometers were exposed to a radiant source of about $60 \mathrm{~kW} / \mathrm{m}^{2}$ in order to check the good 613 agreement (Table A). In the first test, one radiometer was exposed to a smoke plume about 50 $614 \mathrm{~cm}$ above the flame for $200 \mathrm{~s}$. After exposure, the measurements of the heat flux gauge 615 exposed to smoke were compared to those of the soot-free reference radiometer. In the second 616 test, the radiometer was exposed to the flame for $60 \mathrm{~s}$, and the measurements obtained were 617 compared with those of the reference radiometer. The attenuation of the gauge reading after 618 smoke exposure was not significant. These results confirm that the deposition of soot on the 619 gauge window can be considered as negligible when the transducer is only exposed to smoke 
620 (in the preheating region, for instance). This is due to the well-ventilated nature of the flame

621 in the open in contrast with fire in an enclosure. In contrast, flame contact with the gauge 622 deposited a significant quantity of soot on the window. In this case, the attenuation measured 623 during this test was about $25 \%$; therefore, radiation measurement in the flaming region could 624 no longer be considered. When the radiometer is used in a hostile flame environment, 625 nitrogen purging is used to prevent soot deposition in order to keep the radiation transmitting 626 window clean. The purge system requires the use of an inert gas which flows ahead of the 627 window to prevent soot from depositing on it. Another alternative is the use of ellipsoidal 628 radiometers with gas purging to prevent soot from entering its cavity. 